\title{
Estética melodramática e canção popular como lugares de encontros culturais em Bolero, de Lisandro Otero
}

\author{
Melodramatic aesthetic and popular song as places of \\ cultural meetings in Bolero, by Lisandro Otero \\ Wanderlan da Silva Alves \\ Universidade Estadual da Paraíba - Paraíba - Brasil
}

\begin{abstract}
Resumo: Neste artigo, analisam-se os processos de apropriação de elementos associados à estética melodramática e à canção popular na configuração temático-formal do romance Bolero (1983), do escritor cubano Lisandro Otero. Para isso, observa-se como o diálogo empreendido, na literatura, entre os agentes do cancioneiro popular - letras de canções, técnicas de composição, imagens de cantores e compositores, ritmos, etc. - e do campo da ficção, especialmente a recriação livre a partir de indivíduos e situações cujas referências dialogam com possíveis personagens e situações reais, pulverizando-os ao mesmo tempo, de modo a evitar a identificação unívoca e biográfica, presta-se a uma homenagem aos ícones da canção popular latino-americana, bem como potencializa uma leitura crítica tanto de sua constituição quanto das transformações operadas em seu interior, em meio ao desenvolvimento e às ações da indústria cultural estrangeira e a uma imaginação melodramática.
\end{abstract}

Palavras-chave: Canção popular; Cultura de massa; Melodrama; Transculturação

\begin{abstract}
In this article, I analyze the processes of appropriation from elements connected with melodramatic aesthetic and the popular song for the writing of Bolero, Lisandro Otero's novel published in 1983. Then, I show how the literary dialogue created between universe of the popular song - song lyrics, modes of composition, singers and composers' portraits, rhythms, etc. - and the fictional creation with references to individuals and situations similar to real contexts, it avoids biographical identifications, and those procedures offer a tribute to the popular Latin American singers. Beyond that, his narrative promotes a critical reading about the constitution and the changes of the popular song in Latin America in relationship with the actions of foreign cultural industry and a melodramatic imagination.
\end{abstract}

Keywords: Popular song; Mass culture; Melodrama; Transculturation

O escritor cubano Lisandro Otero (1932-2008), cuja obra literária desenvolveu-se especialmente no âmbito da narrativa de caráter histórico, publicou no início dos anos 1980 um romance que se coaduna à estética melodramática. Com Bolero (1983), o autor não só abriu sua obra para o desenvolvimento de uma narrativa pautada nos signos da cultura de massa, mas também construiu uma ficção que se serve da canção popular latino-americana como elemento temático-formal e como núcleo cultural inserido no plano da história. Nesse sentido, Bolero constitui-se numa narrativa que, internamente à diegese, assume a mesma perspectiva dos elementos temáticos que adota, e dialoga tanto com a cultura popular quanto com elementos da cultura de massa, dando voz a categorias culturais e individuais historicamente relacionadas ao universo do cancioneiro popular na América Latina, como o bolero, a guaracha, o son, o tango, o guaguancó, etc., no plano musical, e os cantores populares, seu público, e o universo periférico que não só acolhe suas canções, mas também alimenta as mitologias por vezes difundidas por elas, no tecido social. Desse modo, o romance apresentase como uma espécie de história romanceada da canção popular na América Latina, que adere, em sua tessitura, às possibilidades realistas de representação pela literatura e à tradição, de certo modo, escapista da literatura de caráter sentimental e melodramática voltada ao grande público. Otero admite tratar-se de um projeto há muito tempo em preparação: 
Em Bolero, tratei de incursionar nos mecanismos da criação artística, em tudo aquilo que pode induzir a um "escape à dimensão imaginária": as humilhações, a dor, a alegria, a consternação e a exaltação, a excitação e o amor. Não me surpreendeu porque já fazia tempo que eu estava pensando em empreender um projeto como esse. (HOZ, 2003, p. 6) $)^{1}$.

A abertura ao "escape à dimensão imaginária" de que fala Lisandro Otero desempenha função construtiva no relato, estabelecendo-se como um pressuposto norteador de sua configuração temático-formal, ao mesmo tempo em que dialoga com antecedentes literários do século XIX, especialmente em relação a uma perspectiva de representação realista. Por outro lado, não parece haver uma identificação plena entre a instância da história narrada e a instância enunciativa do relato, numa relação cujos interstícios marcam, também, a distância crítica potencializada pela narrativa. Nesse sentido, Bolero constitui-se numa narrativa fragmentada cuja perspectiva realista é, também, uma paródia às próprias técnicas de representação herdadas do romance realista do século XIX.

Sua diegese narra a biografia de Esteban María Galán ou, simplesmente, Beto Galán, como é mais conhecida a personagem, que é um cantor popular cubano, e a história narrada inicia-se com um flash-back por meio do qual se apresenta a morte do protagonista em razão de uma cirrose. A cena inicial da narrativa, apresentada pela personagem jornalista Agustín Esquivel, já aponta para o estilo que norteia a diegese, pois a cirrose constituise num motivo que se circunscreve ao universo das narrativas melodramáticas, por meio de um diálogo que tem por antecedente mais imediato o melodrama cinematográfico, mas que retoma, também, elementos do romantismo, conforme lembra Silva Oroz (1992). Porém, ao ser vitimado por consequências do alcoolismo, sua morte não porta o mesmo efeito de "glamour" que o motivo da doença portava no contexto do romantismo literário. Ao contrário, parece apontar para o atraso social latino-americano e para o caráter marginalizado da personagem, no plano da narrativa, o que "situa o protagonista no mesmo patamar sócio-cultural dos tuberculosos cinematográficos: artista decadente, termina a vida perambulando pelos ambientes onde se situa" (SANTOS, 1993, p. 179).

A história narrada em Bolero desenvolve-se, basicamente, a partir de três eixos inter-relacionados: Beto Galán, sinédoque do cantor popular latino-americano dos anos 40 e 50 do século XX; a relação conflituosa entre

\footnotetext{
Todos os textos teóricos ou críticos em língua estrangeira empregados neste artigo apresentam-se aqui em tradução livre de nossa autoria. Citações a textos literários foram mantidas no idioma original.
}

Beto e Olimpia; e a canção popular latino-americana, de modo geral ou, especificamente, a canção de Beto Galán. Tais eixos estão imbricados porque todas as personagens da narrativa, salvo o jornalista Agustín Esquivel, estão envolvidas com o universo da canção popular pela condição de cantores, músicos, ouvintes, estudiosos do tema, como é o caso da personagem El Profesor, ou, ainda, por ser crítico musical, como ocorre com a personagem Doctor Arturo.

Visto que a narrativa não está conduzida pela voz de um narrador onisciente, mas pelos diversos depoimentos que o jornalista Agustín Esquivel coleta sobre Esteban María Galán depois de sua morte, o conflito dramático sustentase pelas relações (ora divergentes ora convergentes) estabelecidas entre os relatos das personagens a respeito de Beto ou de Olimpia. Desse modo, esse romance estrutura-se pela justaposição de vozes que constituem variações sobre o tema e, nesse sentido, correspondem a uma espécie de composição melodramática marcada pelo contraponto, que segue as linhas narrativas das letras de bolero, marcadas por paixões intensas, pela impossibilidade da realização plena nas relações amorosas e a presença ou força aterradora do destino.

A própria biografia de Esteban María Galán apresentada em Bolero colabora para a configuração melodramática da narrativa. De origem pobre, Beto Galán, segundo El Profesor, "Era hijo del amor maldito, del más execrable tabú, de la concupiscencia en todas las edades" (OTERO, 1983, p. 10), isto é, era filho de uma relação incestuosa entre pai e filha, a qual a mesma personagem El Profesor interpreta à luz do mito de Esmirna. Por um lado, há no procedimento a opção pelo recurso à imaginação livre, que opera por analogias e que se liga ao caráter de anedota das histórias que compõem as versões biográficas acerca da vida de Beto Galán, ajustando-se às matrizes melodramáticas da narrativa. Ao mesmo tempo, o procedimento estabelece pontos de conexão entre a produção cultural latino-americana e a europeia, numa síntese que procura aproximar o local do universal, perspectiva transcultural que, em Lisandro Otero, porta certa influência de Alejo Carpentier, discretamente reconhecida na própria dedicatória do romance " $A$ la presencia creciente de Alejo Carpentier" (OTERO, 1983, em folha de rosto, sem número de página). Por outro lado, a abertura da narrativa a explicações de caráter imaginativo sustenta a dinâmica interna da diegese, visto que cria condições para que outras personagens se manifestem a respeito das versões que vão se apresentando sobre a vida do cantor Beto Galán.

A genealogia de Beto Galán inscreve-o no universo do melodrama "por trabalhar ainda, com os quatro mitos da cultura judaico-cristã: o amor, a paixão, o incesto e a mulher" (SANTOS, 1993, p.179), que aparecem 
relacionados para a construção ficcional das origens do cantor e reforçados pela interpretação mitológica dada à sua origem por El Profesor. Porém Beto Galán caracteriza-se, na narrativa, também como sendo um gênio (incompreendido) da canção popular cuja potência criativa é relegada ao segundo plano em detrimento do destaque que o álcool, a boemia e a mal sucedida relação com Olimpia adquirem, levando-o à aniquilação individual e profissional e, definitivamente, à morte. Há, portanto, em sua biografia, ao menos dois aspectos que merecem atenção para a caracterização da narrativa do romance: a relação de identificação da personagem com um ideal de artista (o gênio incompreendido); e sua potencial condição de representante do cantor da canção popular latino-americana dos anos 1930-1950.

Santos (1993) já observou que Beto Galán apresenta em sua configuração como personagem traços difundidos pelo estrelato do cinema. Seu próprio nome (Galán) corresponde ao tipo sedutor, em geral, dos filmes românticos hollywoodianos. Mas Beto Galán constitui-se, ainda, numa espécie de representação do artista popular latino-americano de sua época. Bolero apresenta-se, pois, como um romance de artista, como também o considera Osorio (2003), porém destaca-se desse subgênero pelo fato de que o motivo do artista aparece identificado com um cantor e compositor de música popular, num procedimento em que ganha ênfase a problemática modernidade artística na América Latina, marcada pela sedimentação de temporalidades e estratos socioculturais diversos em meio a processos modernizadores de alcance ou eficácia questionáveis.

De tal modo que a perspectiva adotada por Lisandro Otero é paródica, constituindo-se numa leitura que salda dívida com o passado, reconhece sua influência e, ao mesmo tempo, configura-se como uma leitura singular da história da canção e do cantor populares latinoamericanos, num processo de mediação, pois

O papel do mediador equipara-se ao do agente de contato entre diversas culturas e, desse modo, estamos vendo o romancista que chamamos de transculturador, e reconhecendo que, além de suas qualidades pessoais, atua intensamente sobre ele a situação específica em que a cultura à qual ele pertence encontra-se, bem como as pautas segundo as quais ela moderniza-se. (RAMA, 2008, p. 118)

Beto Galán, o bolerista, o sonero, a personagem da boemia noturna e do universo dos cabarés, é um artista, alguém que procura valores, uma personagem movida pelo impulso de criar uma música nova, total, plena (OSORIO, 2003, p. 2). Ou seja, Beto Galán é uma versão popular do artista concebido como homem do mundo, homem da multidão, "homem que compreende o mundo e as razões misteriosas e legítimas de todos os costumes" (BAUDELAIRE, 1997, p. 16). Lisandro Otero mostra, na escrita de Bolero, uma sensibilidade que associa a arte popular à história e recorre, por um procedimento de adaptação livre, à concepção de artista moderno apresentada por Baudelaire, em seu ensaio "O pintor da vida moderna", por encontrar certas homologias entre sua concepção acerca do artista e a personagem protagonista do romance. Em Bolero, Beto Galán é um indivíduo em quem a arte (popular) e a poesia ressoam, a música popular vibra, e ele próprio é um indivíduo afeito às alegrias efêmeras da vida boêmia e dos amores proibidos.

Construída sob uma perspectiva paródica, a personagem porta todas as características do que a visão baudelairiana entende como sendo o artista, porém distancia-se do modelo justamente porque pertence às esferas populares no tecido social e no campo da arte. Nesse sentido, Beto Galán constitui-se numa espécie de dândi latino-americano cuja alma de artista ocupa-se em "correr ao encalço da felicidade" (BAUDELAIRE, 1997, p.47). A personagem porta um comportamento excêntrico, mas, paradoxalmente, não é rica, não foi criada em meio ao luxo nem está acostumada a ver todos os seus desejos ou suas necessidades individuais satisfeitos, em razão de sua condição social e econômica. Enquanto os dândis difundidos pelos romances ingleses ou franceses, no século XIX, são personagens dotadas de fortunas que lhes permitem investir em suas fantasias e desejos a seu bel-prazer, como lembra Baudelaire (1997), Beto Galán e, por extensão, o dândi latino-americano que ele representa investem na fantasia da arte (popular) como universo de plena realização individual e na boemia, que são, para eles, as únicas alternativas disponíveis para a liberação de subjetividades, seja pela carência econômica, seja pela conjuntura histórico-social constantemente marcada pelo autoritarismo que, de certo modo, marcam suas existências. Desse modo, a semelhança marca, também, a diferença, no recurso paródico.

Tal configuração também se associa ao contexto de transição entre a ditadura de Batista, a Cuba prérevolucionária e o momento inicial da Revolução Cubana de 1959, época em que é ambientada a história narrada em Bolero. Nesse sentido, a narrativa incorpora à configuração da personagem Beto Galán uma concepção de artista moderno - em busca do novo, do original, da arte total - à qual se liga a perspectiva pautada na descentralização dos cânones e dos modelos artísticos propostos pela chamada alta cultura. O procedimento corresponde a uma alternativa de legitimação dos produtos populares e de seu universo como sendo uma perspectiva para ver, compreender e organizar a realidade simbólica posta em cena pelas manifestações sociais em nosso tecido social (OSORIO, 2003). 
A coerência dessa concepção torna-se evidente se considerarmos que Beto Galán é representante de uma época, na América Latina, em que o bolero, o tango e os demais ritmos musicais populares, apesar de já se encontrarem em processo de ascensão comercial sob as ações da indústria da cultura, ainda se vinculam às práticas populares de produção, difusão e circulação cultural e, de certo modo, ligam-se a uma coletividade em vias de transformação (ZAVALA, 2000), da condição de camadas populares à de (aspirantes a) público consumidor dos produtos da cultura de massa, num ponto em que o popular e o massivo tocam-se, no tecido social.

A opção por essa configuração híbrida aponta, ainda, para o caráter sutilmente politizado do romance, que busca alternativas de resistência aos processos de alienação pelos quais os indivíduos e as artes populares passam, em meio aos processos modernizadores que se desenvolvem ao longo do século XX e que, entre os anos 40 e 50, se encontram numa etapa de transição que nos anos seguintes assumiria, de fato, a condição de subdesenvolvimento que marca as sociedades latino-americanas na segunda metade do século XX. Nesse sentido, mesmo sendo uma obra narrativa fragmentada por cortes temporais e pela relatividade dos pontos de vista das diversas personagens, Bolero consegue textualizar certa diacronia da existência das personagens, inserindo-as numa trajetória histórica, como nota Santos (1993).

Entretanto, não se pode esquecer que, na diegese de Bolero, tais questões aparecem representadas a partir dos códigos de uma estética melodramática, de modo que a perspectiva realista adotada pela narrativa configurase numa paródia aos modos realistas de representação difundidos pela estética melodramática que o romance adota como fundamento escritural, e a suposta (ou pretendida) objetividade das personagens em seus relatos a respeito de Esteban María Galán choca-se com seus discursos cheios de descrições marcadas pela adjetivação que reitera o exagero, a inevitabilidade ou força do destino e o sentimentalismo, isto é, acabam denunciando que se trata, concretamente, de projeções melodramáticas criadas por cada uma delas em suas versões dos fatos narrados.

Ganham destaque, então, na narrativa, a adjetivação e os epítetos que reiteram a importância e a intensidade dos sentimentos (na maioria das vezes amorosos) na existência das personagens, como vemos, agora, num trecho relatado por Agustín Esquivel, que trata da separação entre Beto Galán e Olimpia, a pedido dela:

La situación era extrañamente paradójica: Esteban María Galán, el Gran Castigador, el Adonis de las faldas, el inmisericorde seductor, el hechicero, el maravilloso Bebé, la hipnótica estrella, el cautivante mago del bolero romántico, se convertía en el burlador burlado. (OTERO, 1983, p.48)

Além da alusão ao mito de don Juan, originalmente presente em El burlador de Sevilla (1630), de Tirso de Molina, o narrador acentua, no trecho acima, o caráter sedutor de Beto Galán, aproximando-o da imagem de um super-herói do amor, porém o que se conota com a descrição é, de fato, a fragilidade do protagonista, em geral escamoteada pelo mito donjuanesco que o envolve. Beto Galán é um representante do machismo característico as letras de bolero, típico, ainda, no tocante à polarização dos papéis entre o homem e a mulher, nos melodramas cinematográficos latino-americanos, conforme explica Oroz (1992). Temos, então, de ressaltar a presença desse procedimento de exagero presente na narrativa, em relação às personagens, com destaque para Doctor Arturo e Agustín Esquivel.

Se considerarmos, como anteriormente já se apontou, que as personagens por vezes se polarizam no que se refere ao comportamento como cronistas da vida de Beto Galán, notaremos, no procedimento em questão, por um lado, uma estilização do excesso que tradicionalmente caracteriza o discurso melodramático, na fala de Doctor Arturo, que, comentando sobre a separação entre Beto e Olimpia, observa, por exemplo, que "tarde o temprano se atraviesa una suprema prueba y hay que cubrir de acero el corazón sangrante para poder atravesarla" (OTERO, 1983, p. 60), mas, por outro lado, esse mesmo exagero também está presente nos trechos narrados por personagens que criticam o caráter anedótico das informações concedidas por Doctor Arturo, como se dá com Agustín Esquivel que, tratando do mesmo tema, diz:

Olimpia destruyó a Beto porque matándolo podía poseerlo y descubrir su identidad; como en las guerras primitivas: debía beber la sangre del enemigo e ingerir sus entrañas para incorporar sus atributos (Saturno devoraba a sus hijos para que ellos no lo devorasen). Ella deseaba ejercer un señorío titular sobre su desgastado compañero -como la más ruin expoliadora-, y detentarlo como un tesoro hallado al azar, humillándolo, frustrándolo para que resalte aún más su propia deificación. Utilizaba un mecanismo de apoderamiento que funcionaba con numerosos recursos: del pudor a la sumisión, de su hipotética debilidad a la seducción con su cuerpo, del estímulo a la vanidad masculina a la esclavista sujeción reduciéndolo a polvo, pero polvo enamorado como el de Quevedo, porque él deseaba, en cambio, bebérsela, envolverse en sus cabellos, acariciarla hasta llagarle la piel, contemplarla hasta quedarse ciego, morderla hasta que la sangre lo ahogase, así estaba él atado a la mujer, a sus caprichosos atributos: él era un extravagante botín que ella manejaba con tornadizos 
designios y Esteban María no supo que estaba siendo degradado a la categoría de objeto, que su dignidad era violada cada día, en la misma medida en que el negrero reduce al esclavo. (OTERO, 1983, p. 174)

Nesse trecho, Olimpia é identificada por Agustín Esquivel com a vilã dos melodramas cinematográficos dominadora, diabólica, sanguinária -, no que se refere ao objeto de desejo, que corresponde tanto a Beto indivíduo quanto à sua música e seu dom de cantor (pois Olimpia também é uma cantora, que, para muitas personagens, chegou ao reconhecimento público graças a Beto, para outras foi uma vítima dos excessos de Beto Galán, e foi quem o conduziu ao sucesso). Como se pode notar, o procedimento criativo a partir de estilemas típicos da estética melodramática aparece, pois, tanto para ironizar certas personagens - como se dá com o discurso do Doctor Arturo sob a ótica de Agustín Esquivel - quanto para incorporar à narrativa traços do melodrama como gênero marcado pelo sentimentalismo e pelo excesso na expressão das emoções. Desse modo, Bolero também realiza, na trama de sua narrativa, uma ambígua homenagem à estética melodramática a que recorre, estabelecendo com ela uma relação afim às de amor e ódio típicas do gênero.

Tal perspectiva liga-se, ainda, às matrizes melodramáticas desse romance, herdeiras tanto da comédia musical (o vaudeville) quanto do melodrama tragicômico, chegando, posteriormente, ao cinema no que se configuraria, na América Latina, como sendo os "filmes para rir" e os "filmes para chorar", segundo explica Oroz (1992). Desse modo, a textualidade da narrativa dá mostras de uma visão pluralista e, mesmo, perturbadora do campo literário que, ambiguamente, homenageia e desafia, recorrendo, para isso, a diferentes construções ou representações do real, do tempo e da história com os quais dialoga.

Em Bolero, a maior parte do excesso em relação à efusão das emoções e dos sentimentos aparece no que constitui o que anteriormente designamos como sendo um dos eixos constitutivos da diegese, o que trata da relação amorosa entre Beto Galán e Olimpia. Praticamente todas as personagens tratam da relação dos dois, e seus relatos variam da aparente fofoca à condenação (ora a Beto, ora a Olimpia). Nesse sentido, problematiza-se a própria condição de verdade dos fatos apresentados, na medida em que o procedimento adotado produz um efeito de humor, como se nota, por exemplo, na condenação feita a Olimpia por várias das personagens. $\mathrm{O}$ trecho abaixo é parte de um relato da personagem El Profesor:

Estaba persuadido de la maldal raigal de Olimpia: una apóstata y renegada que falseó su comportamiento; una fraudulenta, infiel, falaz, farisaica, pícara, truhanesca comedianta, plagada de tretas, arterías y argucias. Olimpia no podía contarse entre los seres decentes y limpios que honran la tierra, porque era gentuza de mala calaña, perteneciente a la chusma; nació falsaria, se hizo bribona, calavera y maleante: su principal atributo era la astucia y sus condiciones más señaladas: el fingimiento, la afectación y el disimulo. (OTERO, 1983, p. 151-152)

A caracterização de Olimpia - que se liga à tradição literária que remonta ao maneirismo de La Celestina (1499) e o Lazarillo de Tormes (1554) - não pode ser levada rigidamente a sério, pois são evidentes os traços da comédia presentes no modo como a personagem é apresentada nesse trecho, por meio de características e comportamentos identificados com sua genealogia, que, além disso, se coadunam à natureza de certas personagens presentes no imaginário popular incorporado pelo sistema literário ibérico, como a bruxa, o pícaro e o gracioso. Entretanto, não se descarta o efeito de questionamento dos valores acerca do comportamento do homem e da mulher em suas relações amorosas. Nesse sentido, o discurso das personagens também aparece permeado por estilemas provenientes das letras de bolero, que, em geral, adotam uma visão machista em relação ao amor "hay mujeres que nacen para causar la desgracia de los hombres, como decía aquel bolero, y ella [Olimpia] era de esas" (OTERO, 1983, p. 22). Na narrativa do romance, porém, talvez pelo efeito de humor já mencionado, notase uma distopia entre a manifestação, no plano simbólico ou do desejo, a favor de certas instituições sociais como o casamento - pois os discursos sobre o amor seguem, em geral, uma moral pequeno-burguesa - e a não realização amorosa das personagens, especialmente Olimpia e Beto Galán. É também por isso que as personagens acabam procurando suas realizações amorosas pela via do imaginário, especialmente em produtos culturais como a canção de feição romântica, com destaque para o bolero e o tango, mas também a radionovela e o cinema.

Ou seja, a narrativa estabelece com o público uma relação pautada nos princípios históricos da estética melodramática, que se centra no sentimentalismo e nas lágrimas, valendo-se, ainda, de categorias históricas constitutivas do melodrama enquanto gênero, como o melodrama romântico, o melodrama sobrenatural e, também, o melodrama doméstico. No que tais escolhas relacionam-se ao projeto escritural de Lisandro Otero, seu romance aponta para a concepção do autor, já explicitada por ele em entrevista a Bianchi (2003), de que

a democratização da cultura é um traço fundamental de nossa época. A cultura cotidiana, aquela mais próxima ao kitsch ou poncif, tem mais peso nos países onde 
a cultura acadêmica e a formação em nível superior são insuficientes. São mais influentes nos países subdesenvolvidos - como o nosso -, a música, a canção, a moda e o entretenimento do que a chamada alta cultura. (BIANCHI, 2003, p. 8)

E a configuração melodramática da narrativa de Bolero ajusta-se, também, a essa ideia de democratização da cultura que, nessa linha de escrita literária, talvez encontre seus antecedentes no drama burguês de meados dos séculos XVIII e XIX europeus (HAUSER, 1969). Desse modo, a narrativa de Bolero reivindica tanto a estética melodramática quanto a canção popular como matéria narrativa e vias de legitimação da cultura cubana e, também, latino-americana:

Sí, los boleros. Hay que valorar los elementos eróticos en la música cubana, que tiene mucho de sensual; basta con observar la sutil voluptuosidad de un danzón, la lascivia desenfrenada de una rumba; la rumba siempre ha tenido esa intención sensual: es el ataque del macho contra la hembra, hay algo también de la pelea de gallos, el enfrentamiento de dos valores, la confrontación; pero en la rumba también existe el deseo: con la popularidad del rechazo y la atracción se desenvuelve un doble sentimiento amor-odio por el cual se buscan y se rechazan. Lo que sucedió en aquellos años podríamos titularlo La rumba de Olimpia y Beto. (OTERO, 1983, p. 25)

Essa vinculação entre a canção e o melodrama encaminha a discussão para o segundo aspecto da constituição da personagem Beto Galán, isto é, como sinédoque do cantor popular latino-americano dos anos 1930-1950, e deve-se, também, à sua associação possível com outros referentes do universo musical, uma vez que, ao estabelecer um diálogo referencial com a biografia de alguns cantores populares da América Latina da época, a narrativa faz de Beto Galán uma espécie de protagonista coletivo, sendo, pois, ao mesmo tempo, uma síntese dos ídolos do cancioneiro popular, no plano da representação, e uma homenagem à canção popular, no campo cultural. Por um lado, há o diálogo com traços biográficos do cantor Benny Moré e de Daniel Santos (ACOSTA, 2003), o que, de certo modo, constitui a base realista referencial da diegese. Por outro lado, no entanto, como Lisandro Otero já tinha sublinhado em entrevista a Pedro de La Hoz, tal substrato realista funciona, na verdade, como um "uma base que serve de sustentação ao verdadeiramente essencial do romance" (HOZ, 2000, p. 6), isto é, à recriação ficcional do universo da canção popular latino-americana dos anos 1930-1950, aproximadamente, a partir de seus nomes, mitos, símbolos e de uma releitura de seus valores.
É, também, nesse sentido que "Lisandro Otero [...] traduz os arquétipos predominantes na cultura popular e seus enganos: o machismo e seu contrário (el hembrismo), suas contrapartidas, os papéis sociais impostos a uma realidade, que nem sempre se consegue imitar" (GONZÁLEZ, 2003, p.2). Desse modo, Bolero constitui-se numa narrativa difusa em relação aos referentes com os quais dialoga, pois sua diegese tanto insere a narrativa no plano da história das classes populares quanto se fundamenta no plano representacional da ficção. Tal procedimento, pelo flerte ambíguo com referentes localizáveis no universo da cultura popular, ao mesmo tempo estabelece uma relação problemática de referência com nomes da canção popular e problematiza essa atividade de referência, de modo que os modelos referenciais multiplicam-se. Logo, a narrativa chama a atenção para os contextos que a tradição cultural ocidental normalmente silencia, tais como o universo da canção e do artista periféricos, além das questões étnicas associadas à mestiçagem, e socioeconômicas ligadas à dependência sociocultural.

Segundo Reynaldo González (2003), vários foram os modelos considerados por Lisandro Otero para a configuração da personagem Beto Galán. Em geral, apresentam em comum o fato de serem figuras do universo musical latino-americano. Acosta, por sua vez, cita os nomes de:

Ernesto Lecuona, Miguel Matamoros, Josephine Baker, Agustín Lara, María Grever, Arsenio Rodríguez, Sindo Garay, Moisés Simons, Arcaño, Rita Montaner, Cascarita, Guty Cárdenas, Chano Pozo, Dizzy Gillespie, Charlie Parker, Billie Holliday, John Coltrane, Miguelito Valdés, Pérez Prado, Armando Oréfiche, Pedro Vargas e muitos outros. (ACOSTA, 2003, p. 2)

Acosta ainda observa que a narrativa de Bolero recorre a certos traços como o carisma e a mitificação por parte do público em relação a outros cantores, como Carlos Gardel e, mesmo, Elvis Presley. Tal perspectiva contrasta, por sua vez, com a de Olimpia, visivelmente identificada com os padrões burgueses de aspiração social, na narrativa. Diferentemente de Beto Galán, cuja identidade se assume explicitamente como sendo pertencente ao universo das camadas mais baixas da população, Olimpia identifica-se, desde sua formação cultural, com os produtos, símbolos e ícones da cultura de massa difundidos pela indústria cultural norte-americana:

La adolescencia de Olimpia transcurrió en la década del treinta y en los años cuarenta ella absorbió sus escasos elementos culturales: el cine norteamericano y el ideal 
de vida que proponía. Aspiró asumir el papel de diosa de las grandes estrellas platinadas: Jean Harlow, Carole Lombard, y estaba bien dotada para incorporarse las poses, atributos, dominios y privilegios de una diva. Al iniciar su carrera hizo una gira por Estados Unidos y su gran pesar era no haber permanecido en aquel país; creía que de haberlo hecho a estas alturas estaría en Hollywood compitiendo con Olivia de Havilland, Joan Fontaine, Irene Dunne, Madelaine Carrol y Constance Bennett; adoraba la elegancia de Vivien Leigh, la inocencia de Deanna Durbin, la gracia de Rosalind Russell, la fuerza de Bette Davis, la languidez de Hedy Lamarr, la voz de Judy Garland, el misterio de Marlene Dietrich, la belleza de Greta Garbo, la distinción de Greer Garson; suspiraba con Norma Shearer y Leslie Howard en "Romeo y Julieta" y se regocijaba con Ginger Roger y Fred Astaire en "Cantando en la Lluvia", Vera Ellen en "Un día en Nueva York", Nanette Fabray en The Bandwagon, Doris Day en Pajama game y aún recordaba cuánto se enternecía en su pubescencia oyendo Indian love song cantado por Jeannette McDonald y Nelson Eddie. (OTERO, 1983, p. 36-37)

Nesse sentido, a história narrada opõe Beto Galán a Olimpia, de forma binária, identificando-os, respectivamente, com o coletivismo e o individualismo, de modo a ressaltar a atitude de Beto Galán e criticar a visão neocolonizada de Olimpia. A oposição binária - que se ajusta à composição melodramática da narrativa, tradicionalmente marcada pela definição de papéis e lugares categoricamente localizáveis no tecido social colabora, ainda, para uma crítica à postura das camadas médias do país, no período da Revolução Cubana, uma vez que, paralelamente à adesão popular às propostas da revolução, a "burguesia cubana, umbilicalmente vinculada à economia norte-americana e suas ramificações em Cuba, não titubeou em abandonar o país, à espera de que uma nova intervenção de Washington a recolocasse no desfrute de seus privilégios na Ilha" (SADER, 1985, p. 56).

A narrativa de Lisandro Otero constitui-se, pois, em “expressão do suceder temporal dos fenômenos sociais, [articulando-os] à vivência histórica do homem, do sujeito comum cuja vida no tecido social é um ato impregnado de problemática e conflito" (MARCELOPÉREZ, 2007, p.78). Por meio desse conjunto de procedimentos cujas políticas de representação não deixam de ser, também, representações politizadas, Bolero postula-se como uma narrativa marcada por uma complexa relação entre o popular e o massivo. Certo modo, Bolero é, também, uma narrativa perpassada por certo saudosismo, especialmente no que se refere à forte adesão popular à revolução de 1959, que, na época, revigora, em certa medida, a importância histórica da presença popular na constituição política e cultural de $\mathrm{Cuba}^{2}$.

Estruturalmente, a diegese do romance recorre à representação do universo popular, seus tipos e seus gostos, na América Latina dos anos 40-50 do século $\mathrm{XX}$, aproximadamente, em consonância com a histórica atitude de resistência das camadas populares cubanas às investidas neocoloniais dos Estados Unidos, desde fins do século XIX. O caráter festivo e gregário da cultura popular a que a narrativa de Bolero relaciona Beto Galán tem certa correspondência com o potencial de insubordinação ideológica das classes populares, de modo que o procedimento de carnavalização da representação política a partir do universo das camadas populares manifestase, também, como ação politizada, na história narrada. A estratégia consiste em recorrer à maneira mais conhecida de mobilizar a comunidade inteira, pela via das festas populares (HOBSBAWM, 1998). Por outro lado, essa combinação herdeira do ritual e da diversão coletiva (que também se coaduna às heranças das culturas africanas na formação sócio-histórica de Cuba) dá ênfase a todas as instâncias envolvidas no ato enunciativo da narrativa de Bolero, de modo que texto, produtor, receptor, contexto histórico e social reestabelecem "uma espécie de projeto comunitário (muito problemático)" (HUTCHEON, 1991, p. 153).

A potência estética e politicamente expressiva do recurso, na narrativa do romance, está em aproximar do universo simbólico do presente dos indivíduos representados uma capacidade crítica originalmente constitutiva de certos rituais das culturas populares afrocubanas. Por essa via, "el montuno insiste en el mismo tema y va hipnotizando al auditor, le va despertando los sentidos, le crea una hiperestesia y logra que perciba la realidad exageradamente" (OTERO, 1983, p. 25). Num procedimento que porta certas analogias com a música e o sexo - dois elementos constitutivos, também, da atmosfera das festas populares: o erotismo e a alegria -,

\footnotetext{
A história da independência cubana, bem como o processo insurrecional que leva à Revolução Cubana de 1959, estão marcados pela participação popular (SADER, 1985). Na chamada primeira guerra pela independência de Cuba, entre 1868 e 1878, dirigida por proprietários rurais da ilha, já era notável a participação das camadas populares, tanto ex-escravos que formaram as tropas para lutar contra os espanhóis quanto líderes populares, como o mulato Antonio Maceo e seus irmãos. Na década de 1920, por sua vez, o ditador Gerardo Machado reprimiu sistematicamente uma significativa oposição popular a seu governo. Em 1932, quando Fulgencio Batista assume o poder, por meio do golpe militar que depõe Gerardo Machado, o movimento também se dá em meio a pressões populares que reivindicam a democracia, e quando Batista assume o governo, Cuba está envolvida em uma intensa mobilização do povo. Ainda na década de 30 , o governo de Prío Socarrás será marcado pelo apoio popular, especialmente entre a juventude, quando surge, no cenário político cubano, a figura de Fidel Castro. E o processo da Revolução propriamente dita mobilizou o "descontentamento do povo contra as condições de miséria, corrupção, falta de liberdade, dependência" (SADER, 1985, p. 5) para o êxito da ação de tomada do poder, em 1959. Independentemente da avaliação que se faça do histórico político cubano e de suas lutas pela democracia, pode-se ressaltar, nele, a expressiva participação popular, e a narrativa de Bolero dialoga com tal ideia para a sua constituição.
} 
um dos efeitos parece ser, nesse sentido, a percepção da realidade que cerca o indivíduo ligado ao universo popular representado na narrativa. A ação da música cubana, de origem africana, em tal contexto, está em que

si bien toda música tiene una significación social, en los negros es más ostensible ese propósito, sobre todo al contraponerla con el arte europeo, que es individualista; en África la música forma parte de la vida del folk y es esencialmente democrática: detrás de la música africana siempre se halla la religión, la ética o el drama y con ella siempre se busca cierto trascendentalismo: el africano puede creer que bailando atrae la lluvia y nunca recurre a los sonidos por mero placer auditivo; los blancos utilizan la música para intensificar las emociones del grupo humano. Además, el africano posee una imaginación animista que dota de corporeidad e identidad a los objetos y a la naturaleza y, al individualizarlos, les entrega potencias con las cuales convive; por ello, las formas diagonales de su arte: el africano siempre está conversando con su entorno, de ahí surgen las maneras antifonales: el solista dice una oración y el coro responde: siempre haciendo un canto plural: es el hombre quien interroga y el mundo el que le responde. Beto intentaba trasladar algo de ello a su música (OTERO, 1983, p. 54).

E essa característica da música de origem africana incorporada à cultura cubana, segundo a personagem El Profesor, parece dotar os elementos da canção popular, na narrativa, de uma capacidade de entretenimento que, no entanto, não descarta seu caráter potencialmente político e social. É preciso destacar, então, que os referentes adotados na narrativa transformam-se, no plano discursivo, de modo que Beto Galán, enquanto personagem, porta traços de muitos outros cantores - incluindo-se na lista nomes de cantoras também -, mas não se limita a nenhum deles e associa-se, ainda, às camadas populares em sentido amplo. Há, nesse procedimento, certo questionamento do discurso referencial pautado numa lógica racional e séria que, no romance, entretanto, se justifica em virtude do entrecruzamento dos componentes do universo musical, pelas reminiscências do caráter popular da música de feição romântica latino-americana dos anos 1930-1950 e, ainda, pelas ações de difusão da canção popular, em geral promovidas pela indústria cultural na América Latina, a partir do fim da primeira metade do século XX, aproximadamente. A narrativa de Bolero parece assumir como parâmetro para tal perspectiva a ideia de que, na história da música popular,

As vidas dos ídolos musicais têm elementos em comum, alguns mais visíveis, coincidentes no tempo, cujas vidas $[. .$.$] representaram um marco de sua conduta,$ ao mesmo tempo em que foram levados por seus próprios esquemas e pela tirania da mercantilização. (GONZÁLEZ, 2003, p. 1)
Nesse sentido, a narrativa desenvolve-se de modo que o diálogo referencial estabelecido com nomes da canção popular funciona como uma alternativa crítica de leitura, pela ficção, da história e do próprio cancioneiro popular latino-americano. Bolero acaba por constituir-se numa ficção romanceada da história da canção popular, mas também da relação de produção e consumo desse produto cultural pelas camadas populares e massivas, centrando-se na fase em que as artes populares e as esferas do poder político tocam-se, em meio às estratégias mercadológicas que inserem a canção popular e seus cantores e compositores na dinâmica do capital.

$\mathrm{Na}$ narrativa de Bolero, o interesse demonstrado internamente ao relato pelos processos de significação nas relações interindividuais e coletivas junto às classes populares associa-se à história dos movimentos populares, o que se liga à representação de indivíduos comuns que, no entanto, dentro do contexto em que aparecem - o da Revolução Cubana -, se constituem em uma esfera política importante, que não pode ser desconsiderada na configuração do tecido social. Os elementos culturais e simbólicos do universo popular deixam de figurar como simples referência para alcançar uma dimensão abrangente que, no campo da arte, se apresenta como prática social, e portam um potencial de resistência à presença crescente e alienante do mercado sobre os produtos culturais.

O próprio processo criativo de Beto Galán situa-se na fronteira entre o popular - identificado com a vocação, a produção artesanal e coletiva, etc. - e o massivo, marcado pelos recursos eletrônicos, a presença do rádio como importante meio de difusão e o disco como ícone dos processos de reprodução da cultura em tal contexto, conforme aponta a personagem El Profesor:

[Beto] andaba buscando lo suyo, algo que no se pareciese a nadie. Como sabía poco de música le cantaba sus melodías al arreglista que las pasaba al pentagrama; a veces tecleaba el piano con los dedos, obteniendo el sonido deseado mientras indicaba dónde la percusión; durante ese proceso no se sabía bien lo que pretendía, siempre el corsi e ricorsi hasta que concluía [...]. Cuando aparecieron las grabadoras le adquirieron una para que dejase en ellas sus esquemas sonoros, pero se paralizaba ante las teclas, decía que andar con botoncitos le hacía olvidar lo que quería expresar. Al comenzar la época de la electrificación acústica, la rechazó hasta que la competencia lo obligó a meterse en el mundo de los woofers y tweeters, de altas y bajas frecuencias, de filtros y estereofonía. (OTERO, 1983, p. 35)

A relação de Beto Galán com a música é marcada pela sensibilidade e pela intuição, e o processo de mecanização na produção de suas canções dá-se em meio à sua resistência. Nesse sentido, a narrativa do romance 
fundamenta-se, também, no que a esfera popular cubana porta como contribuição antropológica à cultura do país. Num relato da personagem Blas Carral, na diegese, lemos: "Todo lo nuestro está en el son: ahí está el origen de la vida, es el pórtico, la ruptura, el semen genitor, la causa y el origen, la concepción y el motivo, el inicio del sendero. Beto se lo había dicho más de una vez" (OTERO, 1983, p.44). De fato, a narrativa estrutura-se na fronteira entre o popular e o massivo, porém imprime certa ênfase sobre os elementos associados ao universo da cultura popular, justamente porque, tendo em vista que não há um corpus já instituído e fechado a seu respeito, Otero encontra na cultura popular elementos expressivos e simbólicos que ainda resistem, ao menos em parte, aos processos de alienação vinculados às ações da indústria cultural e do mercado, em razão da relação ambígua entre o público que consome os produtos provenientes desse universo e a suposta força de determinação mercadológica sobre as ações e o imaginário do público.

Por um lado, a canção popular tematizada na narrativa já está marcada pelas contaminações exógenas à criação propriamente dita - o gosto do público massivo, as chances de venda, as ações empresariais -, no entanto, por outro lado, está marcada, também, por um caráter híbrido que nunca lhe foi alheio e, de certo modo, permanece fiel à sua constituição. Talvez por isso, na diegese, Beto Galán é capaz de atrair públicos oriundos de diversos estratos sociais: "le entraba al son montuno lo mismo que al bolero" (OTERO, 1983, p.41). Ou seja, a relação de Beto com a esfera cultural popular ("el son montuno") ou com o universo já aderido à cultura de massa, mas também associado, nas origens, à cultura popular (por exemplo, o bolero, na América Latina) é flexível a ponto de permitir-lhe um elo entre passado e presente sem descaracterizar, de fato, sua relação de pertencimento ao âmbito popular, também. Quanto a isso, Beto Galán é representativo de certos aspectos positivos da história marcada por colonizações por que passou a ilha de Cuba e, de certo modo, a própria América Latina, ao longo da história, e que, no plano da cultura, dá origem a produtos híbridos esteticamente expressivos em todo o continente, como a música:

¿Podría trazarse el límite entre la percusión cubana y el jazz? Es decir: el momento exacto en que se produce la colisión de ambas fuerzas. Muchos dicen que esa incierta frontera se atraviesa en 1947 cuando Dizzy Gillespie presenta a Chano Pozo en el concierto de Town Hall y Chano a batir lo parches, y emergieron dragones antropófagos, hornos al rojo blanco, fraguas de Vulcano, canículas de agosto, brasas volcánicas, retamas calcinadas de lava, hachones luminosos, aceites borboteantes, sinapismos, vapores de locomotora, sangre espumosa, mientras imprecaba en lucumí, arrastrando a la barbarie y el espanto a aquellos neoyorquinos mesmerizados, hasta que una mujer comenzó a sollozar histéricamente y se desmayó, demostrando que el santo también se le sube a los anglosajones. Otro momento memorable fue cuando Machito se asoció a Charlie Parker para aquella excepcional grabación de "Mango Mangüé". Esa confluencia estaba destinada a ocurrir desde mucho antes por la raíz común de la Gran Madre África. Algunos afirman que se produjo cuando las tropas de ocupación norteamericanas llegaron a Cuba en 1898; venía con ellas William Christopher Handy, el padre de esa variedad de ragtime que se llamó blue, quien fue pianista de uno de los burdeles disfrazados llamados escuelas de baile. (OTERO, 1983, p. 70-71)

A longa explicação sobre a música afro-latinoamericana é dada pela personagem El Profesor, na narrativa, e nela encontramos uma leitura importante a respeito da música em Cuba. Tal leitura aponta para as trocas culturais entre cubanos e norte-americanos no processo de constituição de ritmos musicais influentes em ambos os países, cujas raízes comuns - especialmente a influência africana - funcionam como ponto de conexão entre ambos, o que oferece uma visão pluralista da história da música e da cultura, nos Estados Unidos e na América Latina, ao mesmo tempo em que as coloca em condição de potencial igualdade, pela base ancestral comum. Essa leitura, que não deixa de lado o humor, constrói vias de sentido para a interpretação da importância que a música e os ritmos populares portam para a cultura caribenha e para novas vinculações entre o norte e o sul.

Ao mesmo tempo, essa leitura encontra, no plano histórico da cultura, alternativas simbólicas de relativização das relações historicamente marcadas pela desigualdade, no plano político-econômico. Nesse sentido, Bolero opta pelo que poderíamos chamar de uma reconstituição ficcional de história da canção popular caribenha "de baixo para cima", isto é, encontrando no universo simbólico e estético constitutivo da cultura popular "não um significado político retrospectivo que nem sempre teve; [...] [mas] tentando, mais genericamente, explorar uma dimensão desconhecida do passado" (HOBSBAWM, 1998, p. 219), nesse caso, o potencial cultural e expressivamente relevante das origens africanas como alternativa simbólica de aproximação e coexistência entre as diversas orientações étnicas e ideológicas que constituem a cultura de todo o continente americano.

Não é difícil entender toda essa busca de um passado reconciliador como elemento constitutivo da narrativa de Bolero quando consideramos que o romance foi escrito entre 1982 e 1983, num momento relativamente 
conturbado da história cubana, em que, por um lado, eram notórias as manifestações populares a favor do regime instalado com a revolução de 1959 , mas, por outro lado, a ilha sofria com as investidas contrarrevolucionárias direta ou indiretamente conduzidas com apoio político e financeiro dos Estados Unidos, ao mesmo tempo em que cerca de mais de 100 mil cubanos abandonaram o país (SADER, 1985), situação que se agravaria na década seguinte. Entende-se, desse modo, por que Lisandro Otero refere-se a Bolero, em entrevista a Ciro Bianchi (2003), como sendo um "libro de añoranza". Añoranza que, recorrendo à liberdade de criação a partir de um material cultural marcado pela pluralidade, por relações de continuidade e de rupturas com as tradições anteriores, encontra no passado um vínculo de aproximação com o presente da narrativa e da história, por meio da história da canção popular cubana e afro-latino-americana:

el grito de los tambores cubanos en su euforia: todos son nuestros parientes: hijos, nietos, bisnietos, o abuelos, bisabuelos y tatarabuelos de Chano y Dizzy, de Count Basie y el mágico Jack Teagarden, de Eliseo Grenet y de Ernesto Lecuona, de Jelly Roll y Moisés Simons y Scott Joplin y Rita Montaner, de Sindo Garay, Bola de Nieve, Ignacio Piñeiro, Agustín Lara, Benny Moré, Pérez Prado, Cascarita, Arsenio, Arcaño, Guty Cárdenas, Chacumbele, Felipe Blanco, Gerry Mulligan, María Grever, Charlie Parker; Miguel Matamoros y Archie Shepp; entre todos fabricaron ese compuesto deleitoso y espeso, potable hasta la hez, que Esteban María Galán recibió en legítimo legado, que nació en la Gran Orilla y vino con yorubas, mandingas, carabalíes y congos. (OTERO, 1983, p. 75)

Por meio de tal abordagem das raízes e da configuração híbrida da cultura cubana, Bolero constituise numa narrativa fragmentada cujo contraponto de vozes acaba por tratar tanto da música de Beto Galán quanto da canção popular e, ainda, de sua relação com a cultura em geral. Por essa via, a narrativa acaba por legitimar, também, no campo literário a presença de ritmos musicais populares característicos da cultura latino-americana (especialmente caribenha), ao mesmo tempo em que, como nota Leonardo Acosta (2003), Otero transita por um universo relativamente pouco contemplado antes da década de 1980 pelo romance cubano.

\section{Referências}

ACOSTA, L. Bolero. Cultura literaria, La Habana, p. 1-4, 2003. Disponível em: <www.cubaliteraria.cu/autor/lisandro_otero/ opinionesla.htm>. Acesso em: 30 ago. 2012.

BAUDALAIRE. C. Sobre a modernidade. São Paulo: Paz e Terra, 1997.

BIANCHI, C. He sido desleal a mi vocación. Cultura literaria, La Habana, p. 1-18, 2003. Disponível em: <www.cubaliteraria. cu/autor/lisandro_otero/ciro.htm>. Acesso em: 30 ago. 2012.

GONZÁLEZ, R. Constancia escrita: itinerario a ritmo de bolero. Cultura literaria, La Habana, p. 1-2, 2003. Disponível em: <www.cubaliteraria.cu/autor/lisandro_otero/opinionesra. htm>. Acesso em: 28 ago. 2012.

HAUSER, A. Bajo el signo del cine. In: - Historia social de la literatura y el arte III. Madrid: Ediciones Guadarrama, 1969. p. 271-312.

HOBSBAWM, E. Sobre história. Trad. Cid Knipel Moreira. 2. ed. Companhia das Letras: São Paulo, 1998.

HOZ, P. Lealtad y nación. Cultura literaria, La Habana, p. 1-7, 2003. Disponível em: <www.cubaliteraria.cu/autor/lisandro_ otero/pedro.htm>. Acesso em: 28 ago. 2012.

HUTCHEON, L. Poética do pós-modernismo. Rio de Janeiro: Imago, 1991.

MARCELO-PÉREZ, C. La condición humana y las rutas de la historia en la narrativa de Lisandro Otero. Contexto, v. 11, n. 13, p. 77-87, 2007.

OROZ, S. Melodrama: o cinema de lágrimas da América Latina. Rio de Janeiro: Rio Fundo, 1992.

OSORIO, N. Beto Galán: el sonero como artista. Cultura literária, La Habana, p. 1-3, 2003. Disponível em: <www. cubaliteraria.cu/autor/lisandro_otero/opinionesno.htm $>$. Acesso em: 30 ago. 2012.

OTERO, L. Bolero. La Habana: Contexto audiovisual, 1983.

RAMA, A. Transculturación narrativa en América Latina. 2. ed. Buenos Aires: El Andariego, 2008.

SADER, E. A revolução cubana. 2. ed. São Paulo: Moderna, 1985.

SANTOS, L. Kitsch e cultura de massa na América Latina: a narrativa latino-americana dos anos 70-80. Tese (Doutorado em Literatura Espanhola e Hispano-americana), Universidade de São Paulo, 1993.

ZAVALA, I. El bolero: historia de un amor. Madrid: Celeste, 2000 .

Recebido: 20 de fevereiro de 2015

Aprovado: 09 de junho de 2015

Contato: alveswanderlan@yahoo.com.br 